\title{
Facebook Sosyal Ağına Entegre E-Portfolyo Yazılımının Akademik Başarı ve Öğretim Sürecinde Kullanımına Yönelik Tutuma Etkisi*
}

\begin{abstract}
Hasan ÖZGÜR*
Öz

Gerçekleştirilen araştırmanın amacı Facebook sosyal ağ sitesine entegre edilen e-portfolyo yazılımının öğrenenlerin akademik başarıları ve e-portfolyo sürecine yönelik tutumları üzerindeki etkisinin incelenmesidir. Araştırma, Trakya Üniversitesi Eğitim Fakültesi BÖTE bölümünün üçüncü sınıfında öğrenim gören 69 öğretmen adayının katılımı ile gerçekleştirilmiştir. Çalışmada, öntestsontest kontrol gruplu deneysel model kullanılmıştır. Araştırmada, Geçer ve Dağ (2010) tarafından hazırlanan "Bilgisayar Okur-Yazarlık Ölçeği" ile Demirli (2007) tarafından geliştirilen "E-Portfolyo Öğretim Sürecine Yönelik Tutum Ölçeği” kullanılmıştır. Çalışmada ayrıca, e-portfolyo ile değerlendirmenin, akademik başarı üzerindeki etkisini belirlemek amacıyla araştırmacı tarafından bir akademik başarı testi geliştirilmiştir. Deney grubunda yer alan ve Facebook sosyal ağ sitesine entegre edilen e-portfolyo yazılımını kullanan öğretmen adaylarının eğitim sonucunda elde ettikleri akademik başarı ortalama puanın diğer grupta yer alan sınıf arkadaşlarına kıyasla anlamlı şekilde yüksek olduğu ortaya çıkmıştır. Ayrıca uygulama sonucunda gerçekleştirilen kalıcılık testinde, deney grubundaki öğretmen adaylarının akademik başarı ortalama puanının sınıf arkadaşlarına kıyasla anlamlı şekilde yüksek olduğu ortaya çıkmıştır. Gerçekleştirilen kalıcılık testinde, deney grubunda yer alan öğretmen adaylarının, Facebook sosyal ağ sitesine entegre edilen e-portfolyo yazılımının öğretim sürecinde kullanımına ilişkin tutumlarının olumlu kalmaya devam ettiği ortaya çıkmıştır.
\end{abstract}

Anahtar Kelimeler: E-portfolyo, Facebook, öğretmen adayı, akademik başarı, e-portfolyo öğretim sürecine yönelik tutum.

\section{The Effect of E-Portfolio Software Integrated to Facebook Social Network on Academic Success and the Attitudes towards Its Use in Teaching Process}

\begin{abstract}
The aim of this study is to present the efficiency of e-portfolio software, which was integrated to Facebook social network site. The research sample consists of 69 teacher candidates, who receive
\end{abstract}

\footnotetext{
* Bu çalışma, Trakya Üniversitesi Bilimsel Araştırma Projeleri Koordinasyon Birimince desteklenmiştir. Proje Numarası: 2012/189. Proje Başlı̆̆ı: Facebook Sosyal Ağına Entegre Elektronik Portfolyo Yazılımının Kullanımı ve Sonuçların Değerlendirilmesi.

** Yrd.Doç.Dr. Trakya Üniversitesi, Eğitim Fakültesi Bilgisayar ve Öğretim Teknolojileri Eğitimi Bölümü Edirne/Türkiye, hasanozgur@trakya.edu.tr.
} 
education in third grade of Trakya University Education Faculty Computer Education and Instructional Technologies Department. In the research trial model with control group and pretest-posttest was used. In the research "Computer Literacy Scale" which was prepared by Geçer and Dağ (2010) and "Attitude Related with E-portfolio Teaching Process" scale, which was determined by Demirli (2007) was used. In order to determine the effects of e-portfolio software on academic achievement, an academic achievement test was developed by researcher. As a result of the research it was understood that the academic achievement point average of prospective teachers in experiment group who used the e-portfolio software that was integrated to Facebook were significantly higher than their classmates in the other group. In the follow-up test applied at the end of teaching process it was understood that the prospective teachers in experiment group had a significantly higher average compared to their friends. Also the attitudes of prospective teachers in the experiment group towards e-portfolio software, increased together with the application after their evaluation with the support of e-portfolio software which was integrated to Facebook social networking site. Attitudes related with e-portfolio which integrated to the Facebook social networking site usage in education which demonstrated a positive increase continued to stay positive.

Keywords: E-portfolio, Facebook, prospective teachers, academic achievement, attitude related with e-portfolio teaching process.

\section{GİRIŞ}

Bilim ve teknoloji alanındaki gelişmeler ve yenilikler, hayatın her alanını etkilediği gibi öğrenme ve öğretme sürecinin de değişmesi ve gelişmesinde etkili olmuştur. Bu gelişim ve değişimler ışığında yeni öğrenme kuramları, yöntem ve teknikler öğretim sürecinde kullanılmaya başlanmıştır. Yapılandırmacı değerlendirme yaklaşımı da bu gelişim ve değişimlerden biridir. Geleneksel değerlendirme yaklaşımı öğrenmeyi, ölçmeyi ve öğrenenlerin sınıflandırılmasını amaçlarken, yapılandırmacı değerlendirme yaklaşımı ise ürün ve süreci birlikte değerlendiren ve öğrenenin yapılandırma düzeyini belirlemeye yönelik bir yaklaşımdır (Korkmaz ve Kaptan, 2002; Özden 2003; Schacter, 2000). Alanyazın araştırmaları geleneksel değerlendirme yöntemlerinde kullanılan test ve benzeri ölçme araçlarının; öğrencileri tam olarak değerlendiremediği, öğrenenin performansı konusunda net bir fikir vermediği üzerinde durmaktadır (Lebuffe, 1993; Ryan, 1998; Stiggins, 1999). Bu bağlamda günümüzde, öğrenciyi nasıl değerlendireceğimizin yanı sıra değerlendirmeyi nasıl yapacağımızın da önem kazandı ğı yapılandırmacı değerlendirme yaklaşımında (Stiggins, 1999), öğrenilenlerin daha iyi yansitılabilmesi amacıyla, performans değerlendirme, öz değerlendirme, gözlem, mülakat ve portfolyo gibi değerlendirme teknikleri kullanılmaktadır.

Öğrenilenlerin yanı sıra, öğrenme sürecinin ve öğrenen performansının değerlendirilmesinde kullanılan tekniklerden biri de "bireysel gelişim dosyası (portfolyo) " uygulamasıdır (Grace, 1992; Korkmaz ve Kaptan, 2002; Paulson, Paulson ve Meyer, 1991). Portfolyonun tanımı; kullanım amacı ve biçimine göre farklılık gösterdiğinden, portfolyoyu tek bir tanımla açıklamak mümkün değildir. Grace (1992) portfolyoyu, bireyin öğrenme sürecindeki olaylara ilişkin kayıtları olarak tanımlarken, Black ve Wiliam (1998) ise portfolyoyu, öğrenen tarafından hazırlanmış bir ürünü oluşturan parçalardan ve öğrenenin görüşlerinden oluşan birikim olarak tanımlamaktadır. Daha geniş bir tanımıyla portfolyo, öğrenenin kendi gelişimini, ilerlemesini ve çabalarını değerlendirebilmesi amacıyla bireyin kendisi, arkadaşları, öğretmeni veya meslektaşlarının tavsiyesi ile seçilen, planlı ve amaçlı bir şekilde düzenlenmiş çalışmalar topluluğudur (Barrett, 2000; Ediger,1996; Simon ve Forgette-Giroux, 2000).

\subsection{Elektronik Ürün Dosyası (E-Portfolyo)}

Bilişim ve teknolojideki gelişmeler, önceleri kâğıt üzerinde yapılan portfolyo çalışmalarının elektronik ortamlarda oluşturulmasına ve su- 
nulmasına yol açmıştır. Öğrenciler tarafından oluşturulan ürün ya da ürüne yönelik çalışmaları, elektronik ortamda, farklı teknolojik araçların yardımı ile bir araya getiren yazılım "elektronik ürün dosyası (e-portfolyo)" olarak adlandırılmaktadır. Çayırcı ve Altun (2006)'a göre e-portfolyo, öğrencilerin bir hedefe yönelik olarak hazırladıkları ürünleri hakkında yansıtma ve yorum yapma olanağ 1 sunan çalışmalar bütünü olarak tanımlamaktadır. Öte yandan Cotterill (2007) e-portfolyoyu, öğrenme çıktılarındaki, beceri veya yeteneklerdeki gelişimi gösteren, yararlı bilgi koleksiyonu ve dijital eserler olarak tanımlarken, Mason, Pegler ve Weller (2004) ise e-portfolyo; ürünlerin oluşturulması ile başlayıp, sunulması ile biten süreçte, uygun ürünlerin ve bileşenlerin toplanması, seçilmesi, yansıtılması, yönlendirilmesi ve sunulması gibi çok farklı aşamaları gerçekleştiren yazılım olarak tanımlamaktadır. Tüm bu süreç ve aşamalar ortaya çıkan ürünün yanı sıra bireyin yetenekleri, başarılı olduğu alanlar ve bir süreç içindeki gelişimi, ihtiyaç duyduğu konular hakkında görsel ve dinamik veriler sağladığından, öğrenenin bütüncül değerlendirmesini olanaklı hale getirmektedir. Öğretimde e-portfolyo kullanmanın daha farklı yararları da vardır. Bunlar:

- E-portfolyo ile öğretmenler, öğrencilerin çalışmalarını tekrar tekrar inceleyebilir, bu çalışmalara ilişkin geribildirim sunabilir ve onları yönlendirme imkânına kavuşur (Ahn, 2004).

- Doğru planlandığında, e-portfolyodaki örnekler, öğrenci yeteneklerinin gerçek yansımalarını içerirler (Prus ve Johnson, 1993).

- E-portfolyo ile öğrenciler, multimedya araçlarını amaçları doğrultusunda kullanarak, bilgi ve iletişim teknolojilerinin kullanımı konusundaki becerilerini geliştirme olanağı bulurlar.
- E-portfolyo ile öğrenciler, çalışmalarını okuldan uzakta bile olsalar teslim etme şansına sahip olurlar. Aynı şekilde öğretmenlerde istedikleri yerden çalışmaları kontrol edebilme olanağına kavuşurlar (Wade, Abrami ve Sclater, 2005).

- E-portfolyo öğrencilerin çalışmaya yönelik ilgisini yoğunlaştırır ve program sürecine katılımını sağlar.

Öğretim sürecinde portfolyo kullanımına yönelik gerçekleştirilen çalışmalarda portfolyoların, teori ve uygulama arasında bağlantı oluşturan özelliği ile öğretmen adaylarının hem bireysel hem de mesleki anlamda gelişimine yardımcı olduğu ve portfolyo değerlendirme sürecinde adayın öğretim elemanı ile olan diyaloğunun artmasına vesile olduğu belirtilmektedir (Demir, 2012). Benzer şekilde Pekkanlı (2003), portfolyoların öğretmen adaylarına yararlarını; öğrenmeye güdüleme, sosyal ilişkilerin gelişmesine yardımcı olma, kendi kendini değerlendirmeye olanak sağlama olarak sıralamıştır. Anderson (2005) ile Zeichner ve Wray (2001) ise portfolyonun; öğretmenin mesleğine ilişkin rollerini daha iyi kavramasında, öğretim sürecindeki ilke, yöntem ve teknikleriyle öğrenme kuramlarının daha iyi anlamasında, öğretmenin mesleki gelişimini değerlendirebilmesinde yardımcı olduğunu belirtmiştir.

Tüm bu olumlu yönlerinin yanı sıra, eportfolyolar bazı sinırlılılara da sahiptir. En önemli sınırlılıkların başında da e-portfolyoda yer alan çalışmaların değerlendirilmesinin ve elde edilen verilerin analizinin zaman alması gelmektedir. Ayrıca, performans ve ürün değerlendirme kriterlerinin önceden ve farklı kaynakları (öğretmen, öğrenen, çalışma arkadaşları, veli vb.) kapsayacak şekilde belirlenmesi gerekliliği de e-portfolyoların en belirgin sinırlılıkları arasında yer almaktadır. 
Eğitimde e-portfolyo kullanımına ilişkin gerçekleştirilen bir alanyazın çalışmasında Bahçeci (2006), anatomi dersinde portfolyo kullaniminın, bilişsel ve duyuşsal özellikler üzerindeki etkisini incelemiştir. Çalışma, 215 öğretmen adayı ile gerçekleştirilmiş ve uygulamanın kullanıldığı grupta yer alan öğretmen adaylarının e-portfolyo kullanımı ile akademik başar1larının, erişi ve kalıcılığın arttığı ve duyuşsal özellikler üzerinde olumlu etkiler bıraktığı ortaya çıkmıştır. Benzer şekilde, meslek lisesi öğrencileri ile gerçekleştirilen bir diğer çalışmada Özyenginer (2006), donanım dersini eportfolyo uygulaması ile işlemiş ve öğrencilerin akademik başarısını ve e-portfolyoya olan bakış açılarını değerlendirmiştir. Araştırma sonucunda, öğrencilerin akademik başarısının yüksek düzeyde olduğu ve öğretim sürecinde e-portfolyo kullanımının, öğrencilerin dersle ilgili daha fazla araştırma yapmalarına ve derse daha fazla ilgi duymalarına yol açtığı ortaya çıkmıştır. Erdoğan (2006) tarafından gerçekleştirilen ve askeri lise öğrencilerinin İngilizce eğitiminde e-portfolyo kullanımının, akademik başarı ve tutum üzerindeki etkilerinin araştırıldığı bir diğer çalışmada ise, öğretimde eportfolyo kullanımının akademik başarı ve tutum üzerinde herhangi bir etkisinin olmadığı ortaya çıkmıştır. Çayırcı (2007) tarafından gerçekleştirilen ve ilkokul 7. sınıf öğrencilerinin web tabanlı portfolyo kullanımı ile akademik başarılarındaki değişiminin incelendiği araştırmada ise sözel derslerde web tabanlı portfolyo kullanımının, sayısal derslere kıyasla akademik başarı üzerinde daha olumlu etkileri olduğu ortaya çıkmıştır.

Eğitimde e-portfolyo kullanımına yönelik Salinas, Marín ve Escandell (2011) tarafından gerçekleştirilen bir çalışmada, öğrencilerin sanal öğrenme ortamı ile desteklenmiş bir eportfolyo yazılımına bakış açıları değerlendirilmiştir. Çalışmada öğrencilerin, e-portfolyo yazılımı ile işbirliği ve paylaşımlarının arttığı, proje ödevlerindeki başarılarının arttığı ve kişisel çalışmaları portfolyo dosyası oluşturmak amacıyla saklamanın öneminin kavradıkları belirtilmektedir. Benzer şekilde, Tur ve Marin (2014) tarafından gerçekleştirilen bir diğer çalışmada ise, sınıf arkadaşları ile eportfolyo üzerinden yorumlarını paylaşan öğretmen adaylarının, e-portfolyo notlarının daha yüksek olduğu ve e-portfolyo üzerinden çalışmalara yönelik yorumlarda bulunmanın sosyal paylaşımı arttırdığı sonucuna ulaşmıştır. Öte yandan, Lopez-Fernandez ve RodriguezIllera (2009) tarafından İspanya'da iki farklı üniversiteden 88 öğrencinin katılımı ile gerçekleştirilen bir diğer çalışmada ise öğrencilerin, eportfolyoyu kullanmaktan memnun kaldıkları ve e-portfolyoyu hazırladıkları ödevleri yönetmek için yararlı bir araç olarak gördükleri ortaya çıkmıştır. Mason, Pegler ve Weller (2004), üniversite öğrencilerinin değerlendirilmesi amacıyla bir e-protfolyo yazılımı geliştirmişlerdir. Yazılımı kullanan öğrenciler, yazılımın yaşam boyu öğrenmeyi desteklediğini ve kişisel kariyerleri açısından önemli görülen çalışmaların düzenlemesi amacıyla kullanılabilecek yararlı bir uygulama olduğunu belirtmiştir.

\subsection{Sosyal Ă̆g Sitesi}

Sosyal ăg sitesi, e-posta, anlık mesajlaşma, video, fotoğraf ve yorum paylaşımı gibi özellikleri ile bireylerin birbirleri ile iletişim kurabilmesine ve sosyalleşebilmesine olanak sağlayan ortamlardır (Mooney, 2009). Bazı araştırmacılar ise sosyal ağ sitelerini, kullanıcıların birbirlerine profil bilgileri göndermelerine ve/veya kişisel bilgilerini paylaşmalarına olanak sağlayan, genel veya özel çevrimiçi mesaj gönderimi veya çevrimiçi fotoğraf, video paylaşımı gibi yenilikçi yollar kullanarak bireylerin diğer kişilerle iletişim kurmasına izin veren üye tabanlı İnternet toplulukları olarak tanımlamaktadır (Hew, 2011; Pempek, Yermolayeva ve Calvert, 2009). 
Türkiye'deki sosyal ağ sitelerinin üyelik oranları incelendiğinde, 38 milyon aktif kullanıcı sayısı ile Facebook ilk sırada yer almaktadır. (We Are Social, 2015). Ülkemizde sosyal ağ siteleri içerisinde en çok tercih edilen Facebook sosyal ağ sitesinin (We Are Social, 2015) kullanıcılarının \%34.5'ini, 18-24 yaş aralığındaki üniversite öğrencilerinin de içinde yer aldığı gençler oluşturmaktadır (Socialbakers, 2013). Dünya genelinde Facebook, üniversite öğrencilerinin sosyal ağ sitesi olarak tercih ettikleri ve artan sayıdaki üniversite öğrencisinin sıklıkla giriş yaptığı en popüler platform olarak nitelendirilmektedir (Cheung, Chiu ve Lee, 2011; Kabilan, Ahmad ve Abidin, 2010; Madge, Wellens ve Hooley, 2009; Selwyn, 2009; Sánchez, Cortijo ve Javedc, 2014). Sosyal ağ sitelerinin özellikle gençler ve genç yetişkinler tarafından sıklıkla kullanılması, bu platformların eğitim amaçlı kullanımını ile ilgili çalışmaların yapılmasına yol açmıştır. Gerçekleştirilen çalışmalarda, eğitimde sosyal ağ sitelerinin kullanımının, öğrenenlerin akademik başarıları ve memnuniyetleri üzerinde olumlu etkileri olduğu ortaya çıkmıştır (Callaghan ve Bower 2012; Cerdà, 2012; Ekici ve Kıyıc1, 2012; Lee ve McLoughlin, 2008; Lockyer ve Patterson, 2008; Masic ve Sivic, 2011; Stanciu, Mihai ve Aleca, 2012).

\subsection{Araştırmanın Amacı ve Önemi}

$\mathrm{Bu}$ araştırmanın genel amacı, Facebook sosyal ağ sitesine entegre edilen e-portfolyo yazılımının, etkililiğinin ortaya konulmasıdır. İlgili alanyazın incelemesinde, yabancı dil eğitiminde (Erdoğan, 2006; Erice, 2008; Kennedy, Bruen ve Péchenart, 2012; Tonbul, 2009), mesleki eğitimde (Bahçeci, 2006; Barış, 2011), ilköğretim kademesindeki derslerin öğretimi sürecinde (Başçiftçi, 2011), ortaöğretim kademesindeki derslerin öğretimi sürecinde e-portfolyo kullanımına yönelik (Kutlu, Polat ve Döşlü, 2014) çalışmalara rastlanmaktadır. Benzer şekilde, ilgili alanyazında yükseköğretim kademesindeki derslerin öğretimi sürecinde e-portfolyo kullanımına yönelik (Korkmaz ve Kaptan, 2005; Lopez-Fernandez ve Rodriguez-Illera, 2009; Mason, Pegler ve Weller, 2004; Salinas, Marín ve Escandell, 2011; Sivakumaran, 2005; Tur ve Marin, 2014) çalışmalara da rastlamak mümkündür. Ancak, öğretim sürecinde Facebook sosyal ağ sitesine entegre edilen bir e-portfolyo yazılımı yardımı ile gerçekleştirilen değerlendirme sürecinin öğretmen adaylarının akademik başarıları ve öğretim sürecinde e-portfolyo kullanımına yönelik tutumlarına etkisini inceleyen herhangi bir araştırmanın gerçekleştirilmediği görülmüştür. Ayrıca, ilgili alanyazın çalışmaları, öğretim sürecinde yer alması gerektiği belirtilen e-portfolyo yazılımlarının, akademik başarı ve tutuma olan etkilerinin daha net bir şekilde ortaya çıkarılabilmesi amacıyla farklı ortamlarla desteklenerek sunulması gerektiği üzerinde durmaktadır (Babaee, 2012; Demir, 2012; Kennedy, Bruen ve Péchenart, 2012; Lopez-Fernandez ve Rodriguez-Illera, 2009). Bu bağlamda gerçekleştirilen çalışmadan elde edilecek verilerin, yükseköğretimde eportfolyo kullanımına yönelik bilinç düzeyinin artmasına önemli katkılar sağlaması ve bu alanda yapılacak çalışmalara 1 şı tutması beklenmektedir.

\section{YÖNTEM}

Araştırmada gerçek deneme modellerinden “öntest-sontest kontrol gruplu deneme modeli” kullanılmıştır. Bu modelde yansız atama ile oluşturulmuş gruplar bulunur. Deneme modelleri, neden-sonuç ilişkilerini belirlemek amacı ile doğrudan araştırmacının kontrolü altında, gözlenmek istenen verilerin üretildiği araştırma modelleridir. Bu modelde, deneysel işlemin ne ölçüde etkili olduğuna karar vermek için öntest ve sontest sonuçları birlikte kullanılır. Bu amaçla her grup için öntest ve sontest puanlarındaki 
artışlar bulunarak ortalamalar karşılaştııılır (Karasar, 2012). Araştırmada bağımsız değişkenleri; Facebook sosyal ağ sitesine entegre edilen e-portfolyo değerlendirmesi ve geleneksel sınıf içi değerlendirmedir. Araştırmanın bağımlı değişkenleri ise öğrencilerin akademik başarıları ve e-portfolyo kullanımına yönelik tutum puanlarıdır. Araştırmanın deneysel deseni de Tablo 1'de gösterilmiştir.

Tablo 1. Araştırmada Uygulanan Deneysel Desen

\begin{tabular}{ccccc}
\hline Grup & Öntest & İşlem & Sontest & Kalıcılık Testi \\
\hline Deney & $\begin{array}{c}\text { Tutum ölçeği* } \\
\text { Akademik başarı testi Bilgisa- } \\
\text { yar okur-yazarlık testi }\end{array}$ & $\begin{array}{c}\text { Sosyal ağ sitesine } \\
\text { entegre e- } \\
\text { portfolyo değer- } \\
\text { lendirmesi }\end{array}$ & $\begin{array}{c}\text { Tutum ölçeği } \\
\text { Akademik başarı } \\
\text { testi }\end{array}$ & $\begin{array}{c}\text { Tutum ölçeği } \\
\text { Akademik } \\
\text { başarı testi }\end{array}$ \\
\hline Kontrol & $\begin{array}{c}\text { Akademik başarı testi Bilgisa- } \\
\text { yar okur-yazarlık testi }\end{array}$ & $\begin{array}{c}\text { Geleneksel değer- } \\
\text { lendirme }\end{array}$ & $\begin{array}{c}\text { Akademik başarı } \\
\text { testi }\end{array}$ & $\begin{array}{c}\text { Akademik } \\
\text { başarı testi }\end{array}$ \\
\hline *E-Portfolyo Öğğrim Sürecine Yönelik Tutum Ölç冖̆i & & &
\end{tabular}

* E-Portfolyo Öğretim Sürecine Yönelik Tutum Ölçeği

Tablo 1'den de görüldüğü üzere, rastgele seçilerek oluşturulan deney ve kontrol grubuna, uygulama öncesinde akademik başarı testi uygulanmıştır. Deney grubuna ayrica, eportfolyo öğretim sürecine yönelik tutum ölçeği öntest aşamasında uygulanmıştır. Dokuz hafta süre ile uygulama çalışmaları gerçekleştirilmiş ve hemen ardından kontrol ve deney grubuna aynı akademik başarı testi, sadece deney grubuna ise adı geçen tutum ölçeği sontest olarak uygulanmıştır. Kalıcılık düzeyini belirlenmesi amacıyla, çalışmaların tamamlanmasından beş hafta sonra, söz konusu akademik başarı testi deney ve kontrol grupları tarafından, e-portfolyo öğretim sürecine yönelik tutum ölçeği ise sadece deney grubunda yer alan öğretmen adayları tarafindan tekrar cevaplanmıştır.

\subsection{Evren ve Örneklem}

Araştırma örneklemini, Trakya Üniversitesi Eğitim Fakültesi Bilgisayar ve Öğretim Tekno- lojileri Eğitimi Bölümü'nün üçüncü sınıfında öğrenim gören ve Çoklu Ortam Tasarımı ve Üretimi dersini alan 48 'i erkek (\%69.6) ve $21^{\prime} \mathrm{i}$ kadın (\%30.4) olmak üzere toplam 69 öğretmen adayı oluşturmuştur. Katılımclar seçkisiz atama yoluyla iki gruba bölünerek, deney ve kontrol grupları oluşturulmuştur. Araştırmanın deney grubunda 24 erkek ve 10 kadın öğretmen adayı yer alırken, kontrol grubunda ise 24 erkek ve 11 kadın öğretmen adayı yer almıştır. Seçkisiz atama yoluyla oluşturulan deney ve kontrol gruplarının homojenliğinin değerlendirilmesi amacıyla, öğretmen adaylarının bilgisayar okuryazarlık düzeyleri, Bilgisayar OkurYazarlık Ölçeği (Geçer ve Dağ, 2010) kullanılarak karşılaştırılmıştır. Deney ve kontrol gruplarında yer alan öğretmen adaylarının normal dağılım gösterdiği tespit edilen bilgisayar okuryazarlığı puanlarına ilişkin ortalamalar arasındaki farklılığının test edilmesi amacıyla, ilişkisiz örneklemler t-testi yapılmış ve elde edilen bulgular Tablo 2' de sunulmuştur.

Tablo 2. Deney ve Kontrol Gruplarının Bilgisayar Okuryazarlığı Puanlarına Illişkin t-Testi Sonuçları

\begin{tabular}{lcccccr}
\hline Grup & $\mathrm{N}$ & $\overline{\mathrm{X}}$ & $\mathrm{S}$ & $\mathrm{sd}$ & $\mathrm{t}$ & $\mathrm{p}<$ \\
\hline Deney & 34 & 165.79 & 15.38 & 67 & -.25 & .800 \\
Kontrol & 35 & 166.66 & 13.30 & & & \\
\hline
\end{tabular}

Tablo 2 incelendiğinde, deney grubunun bilgipuan ortalaması ( $\overline{\mathrm{X}}=166.66)$ arasinda anlamlı bir sayar okuryazarlığı puan ortalaması ( $\overline{\mathrm{X}}=165.79)$ ile kontrol grubunun bilgisayar okuryazarlığ farklılık saptanmamıştır $[\mathrm{t}(67)=.25, \mathrm{p}>.05]$. Bu bulgu, grupların bilgisayar okuryazarlığı puan 
ortalamaları arasında bir fark olmadığını ve grupların uygulama için birbirine denk olduğunu kanitlar niteliktedir.

\subsection{Veri Toplama Araçları}

Akademik Başarı Testi: E-portfolyo yazılımının akademik başarı üzerindeki etkisinin belirlemek amacıyla hem kontrol hem de deney grubunun "Çoklu Ortam Tasarımı ve Üretimi" dersindeki akademik başarı düzeylerindeki değişimi ortaya çıkaracak bir akademik başarı testi geliştirilmiştir. Testin geliştirilme sürecinde, alanyazın incelemesi yapılmış ve ders müfredatı gözden geçirilmiştir. Test kapsamında geliştirilen 43 soruluk form daha önce "Çoklu Ortam Tasarımı ve Üretimi" dersini lisans düzeyinde vermiş olan ve farklı üniversitelerde öğretim faaliyetlerini sürdüren üç farklı öğretim üyesine mail aracılığı ile gönderilmiştir. Öğretim üyelerinin uzman görüşleri doğrultusunda, bir sorunun testten çıarılmasına karar verilmiştir. Kavram yanılgısına sebep olabilecek diğer soruların ilgili bölümleri düzenlenerek, soruların ayırt edicilik ve güçlük değerlerinin belirlenmesi amacıyla daha önce adı geçen dersi almış olan ve farklı üniversitelerin BÖTE bölümlerinde öğrenim gören 110 öğretmen adayına akademik başarı testi uygulanmıştır. Elde edilen veriler sonucunda, ayırt edicilik ve güçlük değeri uygun olmayan iki soru daha testten çıkarılarak, madde güçlüğü .48 olan ve orta güçlük değerine sahip bir akademik başarı testi elde edilmiştir. 40 soruluk akademik başarı testinden alınan puanların iç tutarlılık katsayıları .89 ile .92 arasında değiştiği ortaya çıkmıştır. Testin birbirine eşit iki ayrı yarıya ayrılmasına yönelik olarak bulunan Guttman ve Spearman-Brown katsayıları sıraslyla .91 ve .92 'dir. Testin güvenirliğine ait KR20 değeri ise .89 olarak bulunmuştur. Bu bulgular hazırlanan akademik başarı testinin tutarlı olduğunu kanıtlar niteliktedir.
Bilgisayar Okur-Yazarlık Ölçĕ̆gi: Araştırmada, öğretmen adaylarının bilgisayar okuryazarlık düzeylerinin belirlenmesi amaciyla Geçer ve Dağ (2010) tarafından hazırlanan "Bilgisayar Okur-Yazarlık Ölçeği" kullanılmıştır. Ölçek 40 madde ve tek faktörden oluşan bir ölçektir. Ölçeğin iç tutarlılık katsayısı .97 ve söz konusu ölçekten bir öğrencinin alabileceği puan 40 ile 200 arasındadır. Ölçek, 1-hiç, 2-çok sinırlı, 3biraz, 4-oldukça iyi, 5- çok iyi olmak üzere beşli derecelendirme ile yantlanmakta olup ölçekten alınan puanın yüksekliği bireyin bilgisayar okur-yazarlık düzeyinin yüksek olduğunu göstermektedir (Geçer ve Dağ, 2010).

E-Portfolyo Öğretim Sürecine Yönelik Tutum Ölçe$\breve{g} i$ : Öğretmen adaylarının e-portfolyo kullanımına yönelik tutumlarını belirlemek ve katılımcıların adı geçen tutumlarındaki değişimi gözlemek amacıyla ise Demirli (2007) tarafından geliştirilen "E-Portfolyo Öğretim Sürecine Yönelik Tutum Ölçeği” kullanılmıştır. Ölçek 38 madde ve tek boyuttan oluşan bir ölçektir. Ölçeğinin iç tutarlılık katsayısı .93 ve söz konusu ölçekten bir öğrencinin alabileceği puan 38 ile 190 arasındadır. 5- tamamen katılmıyorum, 4- katılmiyorum, 3- kısmen katıliyorum, 2katılıyorum, 1- tamamen katıliyorum olmak üzere beşli derecelendirme ile yanttlanan ölçekten alınan puanın yüksek oluşu katılımcının eportfolyo kullanımına yönelik tutumlarının olumlu olduğunu işaret etmektedir (Demirli, 2007).

\subsection{Verilerin Analizi}

Araştırmada elde edilen veriler, istatistiksel çözümlemelerinin gerçekleştirilmesi amacıyla araştırmacı tarafından bilgisayar ortamına aktarılmıştır. Elde edilen niceliksel verilerin analiz işlemlerinde, aritmetik ortalama ve standart sapmalar SPSS 21 programı aracilığı hesaplanmıştır. Grup içi karşılaştırmalar tek örneklem Kolmogorov-Smirnov Z testi ile dağılımın normal olup olmadığı test edilmiştir. 
Kontrol ve deney gruplarının bilgisayar okuryazarlığı, e-portfolyo öğretim sürecine yönelik tutumları ve akademik başarı test puanlarının istatistiki analizleri için ise ilişkisiz ve ilişkili gruplar t-testleri ile ilişkili örneklemler için tek faktörlü ANOVA testi uygulanmıştır.

\subsection{Deneysel İşlem Yolu}

E-Portfolyo yazılımı (https://apps.facebook .com/e-portfolyo/), asp.net yazılım dili kullanılarak geliştirilmiştir. Yazılım geliştirme sürecinde, alan uzmanları ve öğretmen adayları eşliğinde biçimlendirici değerlendirmeye tabii tutulmuştur. Bu süreçte kodlama aşamasında fark edilmeyen hatalar giderilmiştir. Ayrıca insan bilgisayar etkileşimi kapsamında; ekran tasarımı, menü yerleşimi, metin düzeni ve yazı karakteri gibi görsel unsurlar ve kullanılabilirlik sıkıntısı yaratan parçalar ile kısa süreli bel- leğe bilişsel anlamda yük getireceği düşünülen öğeler tekrar gözden geçirilerek gerekli düzenlemeler yapılmıştır. Biçimlendirici değerlendirme sonucunda üç alan uzmanı ve 10 öğretmen adayından oluşan bir grup, yazılımı kendi derslerinde kullanmıştır. Öğretim üyelerinden ve öğretmen adaylarından alınan erişi değerlendirmeye yönelik geribildirimler ile yazılım uygulama öncesi son halini almıştır. Değerlendirme süreci tamamlanan e-portfolyo yazılımının öğrenci ve eğitmen ara yüzleri Şekil 1'de sunulmuştur. Ayrıca Facebook sosyal ağ sitesini eğitsel amaçlı kullanan eğitmenlerle görüşülüp, sayfa tasarımı ve içerik geliştirme sürecine yönelik önerileri değerlendirilerek üyelere özel Facebook grubu ve sayfası oluşturulmuştur (https://www.facebook.com/groups/1415618945 353540/).

\section{Şekil 1. E-Portfolyo Yazılımının Öğrenci ve Eğitmen Ara Yüzü}

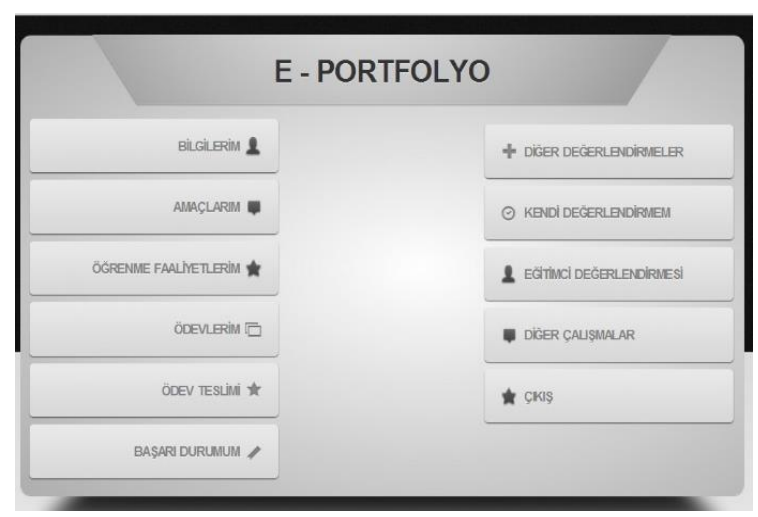

\section{BULGULAR}

Araştırma kapsamında geliştirilen Facebook sosyal ağ sitesine entegre olarak çalışan eportfolyo yazılımı dokuz hafta süre ile gerek öğretim üyesi gerekse deney grubunda yer alan öğretmen adayları tarafından ödevlerin değerlendirilmesi amacıyla kullanılmıştır. Eğitim süresinin sonunda Çoklu Ortam Tasarımı ve Üretimi dersinin konularını kapsayan ve ön test olarak sunulan akademik başarı testi, son test olarak tüm öğretmen adaylarına tekrar

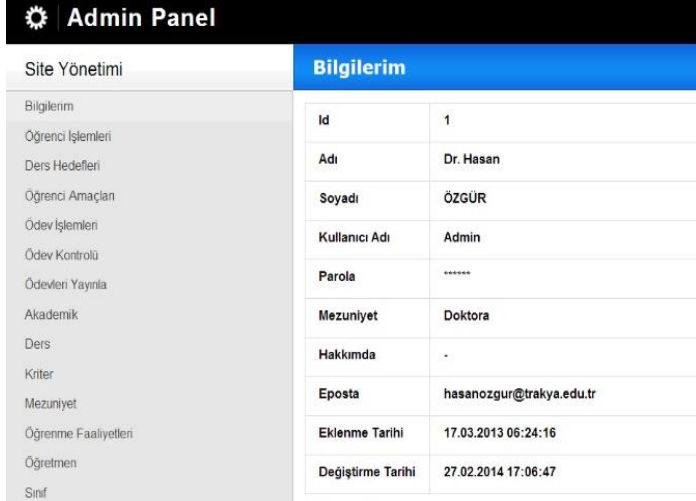

uygulanmıştır. Ayrıca deney grubunda yer alan öğretmen adaylarından e-portfolyo sürecine yönelik tutumlarındaki olası değişimlerin tespiti için de daha önce gerçekleştirilen “EPortfolyo Öğretim Sürecine Yönelik Tutum Ölçeği"ni tekrar yanıtlamaları istenmiştir.

Deney ve kontrol gruplarının akademik başarı öntest, sontest ve kalıcılık testlerinin betimsel istatistikleri Tablo 3’te verilmiştir. 
Tablo 3. Deney ve Kontrol Gruplarında Yer Alan Öğretmen Adaylarının Akademik Başarı Testlerine İlişkin Betimsel İstatistikleri

\begin{tabular}{|c|c|c|c|c|}
\hline Başarı testi & Grup & $\mathrm{N}$ & $\overline{\mathrm{X}}$ & Ss \\
\hline \multirow[t]{3}{*}{ Öntest } & Deney & 34 & 25.52 & 7.35 \\
\hline & Kontrol & 35 & 26.15 & 7.56 \\
\hline & Toplam & 69 & 25.83 & 7.47 \\
\hline \multirow[t]{3}{*}{ Sontest } & Deney & 34 & 62.87 & 6.55 \\
\hline & Kontrol & 35 & 55.00 & 11.80 \\
\hline & Toplam & 69 & 58.88 & 9.87 \\
\hline \multirow[t]{3}{*}{ Kalıcilık Testi } & Deney & 34 & 61.99 & 8.34 \\
\hline & Kontrol & 35 & 48.07 & 11.37 \\
\hline & Toplam & 69 & 55.03 & 10.07 \\
\hline \multicolumn{3}{|c|}{$\begin{array}{l}\text { Tablo 3'te sunulan veriler, öğretmen adayları- } \\
\text { nın eğitim öncesi ve eğitim sonrası akademik } \\
\text { başarı testi puanlarına ilişkin betimsel istatistik- } \\
\text { leri ortaya koymaktadır. Akademik başarı } \\
\text { öntest, sontest ve kalıcılık testi uygulamalarına, }\end{array}$} & \multicolumn{2}{|c|}{$\begin{array}{l}\text { Deney grubunda yer alan öğretmen adayları- } \\
\text { nın akademik başarı öntest, sontest ve kalıcılık } \\
\text { testlerinden elde ettikleri puanlara ilişkin ör- } \\
\text { neklemler için tek faktörlü ANOVA sonuçlar } \\
\text { Tablo 4'te sunulmuştur. }\end{array}$} \\
\hline
\end{tabular}

deney grubundan 34 , kontrol grubundan ise 35

öğretmen adayı katılmıştır.

Tablo 4. Deney Grubunun Akademik Başarı Öntest, Sontest ve Kalıcılık Testi Puanlarına İlişkin ANOVA Sonuçları

\begin{tabular}{lccccccc}
\hline $\begin{array}{l}\text { Varyansın } \\
\text { Kaynağ }\end{array}$ & $\begin{array}{c}\text { Kareler } \\
\text { Toplamı }\end{array}$ & sd & $\begin{array}{c}\text { Kareler } \\
\text { Ortalamas }\end{array}$ & F & p & $\eta^{2}$ & $\begin{array}{c}\text { Anlamlı } \\
\text { fark }\end{array}$ \\
\hline Denekleraras1 & 7621.385 & 33 & 230.951 & & & & \\
Ölçüm & 30896.078 & 2 & 15448.039 & 164.79 & .001 & .83 & $2-1,3-1$ \\
Hata & 6187.255 & 66 & 93.746 & & & & \\
Toplam & 44704.718 & 101 & & & & & \\
\hline 1: Öntest & 2:Sontest & 3: Kalıcllk Testi & & & &
\end{tabular}

Tablo 4'te sunulan bulgular, öğretmen adaylarının uygulama öncesi gerçekleştirilen akademik başarı öntest ortalama puanı ( $\overline{\mathrm{X}}=25.52)$ iken, uygulamadan bitiminden hemen sonra gerçekleştirilen akademik başarı sontest ortalama puanının ( $\overline{\mathrm{X}}=62.87)$ yükseldiği ve farkın da anlamlı olduğunu $\left[\mathrm{F}_{(2,66)}=164.79, \quad \mathrm{p}<.05\right.$; $\eta^{2}=.83$ ] göstermektedir. Elde edilen bulgular ayrıca, uygulamanın bitiminden beş hafta sonra yapılan kalıcılık testi ölçümünden elde edilen ortalama puan $(\overline{\mathrm{X}}=61.99)$ ile sontestten elde edilen ortalama puanının birbirine çok yakın olduğu ve farkın da anlamlı olmadığı ortaya çıkarmıştır. Bu bulgu, uygulama ile birlikte öğretmen adaylarının uygulama kapsamında öğretilen konuları öğrendiklerini ve öğrenilen bilgilerin beş hafta sonra da hatırlanmaya devam edildiğini göstermektedir.

Kontrol grubunda yer alan öğretmen adaylarının akademik başarı öntest, sontest ve kalıcılık testlerinden elde ettikleri puanlara ilişkin ilişkili örneklemler için tek faktörlü ANOVA sonuçları Tablo 5'te sunulmuştur. 
Tablo 5. Kontrol Grubunun Akademik Başarı Öntest, Sontest ve Kalıcılık Testi Puanlarına İlişkin ANOVA Sonuçları

\begin{tabular}{lccccccc}
\hline $\begin{array}{l}\text { Varyansın } \\
\text { Kaynağı }\end{array}$ & $\begin{array}{c}\text { Kareler } \\
\text { Toplamı }\end{array}$ & sd & $\begin{array}{c}\text { Kareler } \\
\text { Ortalaması }\end{array}$ & F & p & $\eta^{2}$ & $\begin{array}{c}\text { Anlamlı } \\
\text { fark }\end{array}$ \\
\hline Deneklerarası & 13424.048 & 34 & 394.825 & & & & \\
Ölçüm & 15885.357 & 2 & 7942.679 & 52.98 & .001 & .61 & $2-1,3-1$, \\
Hata & 10193.810 & 68 & 149.909 & & & & $2-3$ \\
Toplam & 39503.215 & 104 & & & & & \\
\hline 1: Öntest & 2:Sontest Kalıclık Testi & & & & &
\end{tabular}

Tablo 5'te sunulan bulgular, kontrol grubunda yer alan öğretmen adaylarının akademik başarı öntest ortalama puanı ( $\overline{\mathrm{X}}=26.15)$ iken, akademik başarı sontest ortalama puanının ( $\bar{X}=55.00)$ yükseldiği ve farkın da anlamlı olduğunu $\left[F_{(2,68)}=52.98, p<.05 ; \eta^{2}=.61\right]$ göstermektedir. Elde edilen bulgular ayrıca, kalıcılık testi ölçümünden elde edilen ortalama puan $(\bar{X}=48.07)$ ile sontestten elde edilen ortalama puan arasindaki farkın da anlamlı olduğunu ortaya koymuştur. Bu bulgu, uygulama ile birlikte öğretmen adaylarının uygulama kapsamında öğretilen

Tablo 6.Deney ve Kontrol Gruplarında Yer Alan Öğretmen Adaylarının Öntest Puanlarına Illişkin t-Testi Sonuçları

\begin{tabular}{lcccccc}
\hline Grup & $\mathrm{N}$ & $\overline{\mathrm{X}}$ & $\mathrm{Ss}$ & $\mathrm{sd}$ & $\mathrm{t}$ & $\mathrm{p}$ \\
\hline Deney & 34 & 25.52 & 7.35 & 67 & -.21 & .840 \\
Kontrol & 35 & 26.15 & 7.56 & & & \\
\hline
\end{tabular}

Tablo 6 incelendiğinde; deney grubunun akademik başarı öntest ortalama puanı ( $\overline{\mathrm{X}}=25.52)$ ile kontrol grubunun akademik başarı öntest ortalama puanı $(\overline{\mathrm{X}}=26.15)$ arasinda anlamlı bir farklılık saptanmamıştır $\left[\mathrm{t}_{(67)}=.21, \mathrm{p}>\right.$.05]. $\mathrm{Bu}$ bulgu, grupların akademik başarı öntest ortalama puanları arasında bir fark olmadığını ve grupların uygulama için birbirine denk olduğunu kanitlar niteliktedir.

konuları öğrendiklerini, ancak öğrenilen bilgilerin, uygulamanın tamamlanmasindan sonra unutulmaya başlandığını göstermektedir.

\section{1. Önteste İlişkin Bulgular}

Deney ve kontrol gruplarında araştırmaya katılan öğretmen adaylarının akademik başarı ön test puan ortalamaları arasındaki farklılığın test edilmesi amacıyla ilişkisiz örneklemler ttesti yapılmış, elde edilen bulgular Tablo $6^{\prime}$ da sunulmuştur.

\subsection{Sonteste İliş̧in Bulgular}

Öğretmen adaylarına dokuz hafta süre Facebook sayfasina entegre edilen e-portfolyo yazılımı desteği ile verilen eğitimin akademik başarı üzerindeki etkisini belirlemek amacıyla sontest ortalama puanları üzerinden gerçekleştirilen ilişkisiz örneklemler t-testi sonuçları Tablo 7'de sunulmuştur.

Tablo 7. Deney ve Kontrol Gruplarında Yer Alan Öğretmen Adaylarının Sontest Puanlarına İlişkin tTesti Sonuçları

\begin{tabular}{lcccccc}
\hline Grup & $\mathrm{N}$ & $\overline{\mathrm{X}}$ & $\mathrm{Ss}$ & $\mathrm{sd}$ & $\mathrm{t}$ & $\mathrm{p}$ \\
\hline Deney & 34 & 62.87 & 6.55 & 67 & 2.63 & .027 \\
Kontrol & 35 & 55.00 & 11.80 & & & \\
\hline
\end{tabular}

Tablo 7 incelendiğinde; deney grubunun akaöntest ortalama puanından ( $\overline{\mathrm{X}}=55.00)$ daha demik başarı öntest ortalama puanının $(\overline{\mathrm{X}}=62.87)$ kontrol grubunun akademik başarı yüksek olduğu ve farkında anlamlı $\left[\mathrm{t}_{(67)}=2.63\right.$, $\mathrm{p}<.05]$ olduğu görülmektedir. Bu bulgu, deney 
grubunda yer alan öğretmen adaylarının akademik başarı sontestinden diğer gruba kıyasla daha yüksek puanlar aldığını ortaya koymaktadir.

\subsection{Kalıcılık Testine İlişkin Bulgular}

Öğretmen adaylarına, uygulamanın bitiminden beş hafta sonra uygulanan kalıclık testine ilişkin bulgular Tablo 8' de sunulmuştur.

Tablo 8. Deney ve Kontrol Gruplarında Yer Alan Öğretmen Adaylarının Kalıcılık Testi Puanlarına İlişkin t-Testi Sonuçları

\begin{tabular}{lcccccc}
\hline Grup & $\mathbf{N}$ & $\overline{\mathbf{X}}$ & Ss & sd & $\mathbf{t}$ & $\mathbf{p}$ \\
\hline Deney & 34 & 61.99 & 11.34 & 67 & 4.17 & .001 \\
Kontrol & 35 & 48.07 & 15.95 & & & \\
\hline
\end{tabular}

Tablo 8 incelendiğinde; deney grubunun kalıc1lik testi ortalama puanının ( $\overline{\mathrm{X}}=61.99)$ kontrol grubunun kalıcilık testi ortalama puanından ( $\overline{\mathrm{X}}=48.07)$ daha yüksek olduğu ve farkında anlamlı olduğu görülmektedir $[\mathrm{t}(67)=4.17, \mathrm{p}<.05]$. $\mathrm{Bu}$ bulgu, deney grubunda yer alan öğretmen adaylarının öğrendikleri bilgileri, diğer grupta yer alan arkadaşlarına kıyasla daha iyi hatırladıklarını ya da daha az unuttuklarını göstermektedir.

Tablo 9. Deney Grubunun E-Portfolyo Öğretim Sürecine Yönelik Tutum Öntest, Sontest ve Kalıcllık Testi Puanlarına İlişkin ANOVA Sonuçları

\begin{tabular}{lccccccc}
\hline $\begin{array}{l}\text { Varyansın } \\
\text { Kaynağı }\end{array}$ & $\begin{array}{c}\text { Kareler } \\
\text { Toplamı }\end{array}$ & sd & $\begin{array}{c}\text { Kareler } \\
\text { Ortalaması }\end{array}$ & F & p & $\eta^{2}$ & $\begin{array}{c}\text { Anlamlı } \\
\text { fark }\end{array}$ \\
\hline Deneklerarası & 45451.539 & 33 & 1377.319 & & & & \\
Ölçüm & 478.765 & 2 & 239.382 & 14.99 & .001 & .31 & $3-1,2-1$ \\
Hata & 1053.902 & 66 & 15.968 & & & & \\
Toplam & 46993.206 & 101 & & & & & \\
\hline 1: Öntest & 2:Sontest & 3: Kalıcllk Testi & & & & &
\end{tabular}

Öğretmen adaylarının e-portfolyonun öğretimde kullanımına ilişkin tutum ortalama puanı uygulama öncesinde ( $\overline{\mathrm{X}}=139.88)$ iken uygulamadan hemen sonra tutum ortalama puanının $(\overline{\mathrm{X}}=144.82)$ yükseldiği ve farkın da anlamlı olduğu $\left[\mathrm{F}_{(2,66)}=14.99, \mathrm{p}<.05 ; \eta^{2}=.31\right]$ görülmektedir. Uygulamanın bitiminden beş hafta sonra tekrar yapılan tutum ölçümünde ise sontestte elde edilen ortalama puan ile kalıclık testinde elde edilen ortalama puanın ( $\bar{X}=144.03$ ) birbirine çok yakın olduğu ve farkın da anlamlı olmadı ̆̆ı ortaya çıkmıştır. Bu bulgu, uygulama ile birlikte öğretmen adaylarının eportfolyonun öğretimde kullanımına yönelik tutumlarının olumlu yönde değiştiğini ve bu
3.4. E-Portfolyo Öğretim Sürecine Yönelik Tutumlara İlişskin Bulgular

Deney grubunda yer alan öğretmen adaylarına uygulama öncesinde, uygulama bitiminde ve uygulama bitiminden beş hafta sonra gerçekleştirilen e-portfolyo öğretim sürecine yönelik tutum ölçeğinden elde edilen bulgular Tablo $9^{\prime}$ da sunulmuştur. olumlu değişimin de sürdüğünü işaret etmektedir.

\section{TARTIŞMA VE SONUÇ}

Facebook sosyal ağ sitesine entegre edilen bir eportfolyo yazılımının akademik başarı ve tutum üzerindeki etkilerinin incelendiği bu araştırmada, deney grubunda yer alan ve sosyal ağ sitesine entegre edilen e-portfolyo yazılımını kullanan öğretmen adaylarının, eğitim sonucunda elde ettikleri akademik başarı ortalama puanının diğer grupta yer alan sınıf arkadaşlarına kıyasla daha yüksek olduğu araştırmada ortaya çıkan önemli bulgulardan biridir. Araş- 
tırmada elde edilen bir diğer bulgu ise, öğretim sürecinin sonunda yapılan kalıcılık testinde de deney grubunda yer alan öğretmen adaylarının diğer gruptaki arkadaşlarına kıyasla daha yüksek bir ortalamaya sahip oldukları ve öğrenilen bilgileri daha az unuttukları ortaya koymuştur. Başka bir değişle Facebook sosyal ağ sitesine entegre edilen e-portfolyo yazılımı kullanımının, deney grubundaki öğretmen adaylarının öğrenmeleri üzerinde olumlu bir etkiye neden olduğu söylenebilir. Araştırmada ortaya çıkan bu sonuç, bazı alanyazın araştırmalarının sonuçları ile benzerlik göstermektedir (Barış, 2011; Çayırc1, 2007; Erice, 2008; Gürol ve Demirli, 2006; Güven ve Aydoğdu, 2009; Tonbul, 2009). İlgili alanyazında, Kutlu, Polat ve Döşlü (2014) tarafından geliştirilen web tabanlı bir portfolyo yazılımının, onuncu sınıf bilgi ve iletişim teknolojileri dersine ilişkin akademik başarı ve tutum üzerindeki etkisinin incelendiği çalışmanın sonuçları ile Turan ve Sakız (2014) tarafından gerçekleştirilen ve fen ve teknoloji dersinde elektronik portfolyo kullanımının akademik başarı ve tutum üzerindeki etkisinin incelendiği çalışmanın sonuçları da gerçekleştirilen araştırmanın bulguları ile örtüşmektedir. Öte yandan bu bulgu, Erdoğan (2006) tarafından gerçekleştirilen ve öğretim sürecinde e-portfolyo kullanımının akademik başarı ve tutum üzerinde herhangi bir etkisinin olmadığını belirten araştırmanın sonucu ile tutarlılık göstermemektedir. Yürütülen bu araştırma ile alanyazın araştırmasının sonucu arasında ortaya çıkan farkın, öğrenenlerin derse karşı olan tutumlarından, çalışmanın uygulandığı dersin farklılığından ya da öğrenen bireylerin kişisel özelliklerindeki farklılıklardan kaynaklanabileceği düşünülmektedir.

Araştırmanın bir diğer bulgusu ise, deney grubunda yer alan ve Facebook sosyal ağ sitesine entegre edilen e-portfolyo yazılımı desteği ile değerlendirilen öğretmen adaylarının, uygulama öncesinde öğretimde e-portfolyo kullanı- mına yönelik tutumlarının, uygulama ile olumlu yönde değişmiş olmasıdır. Olumlu yönde artış gösteren öğretimde e-portfolyo kullanımına yönelik tutumlar, uygulama bitiminden beş hafta sonra da olumlu kalmaya devam etmiştir. Elde edilen bu bulgu, alanyazın araştırmalarının sonuçları ile desteklenmektedir (Başçiftçi, 2011; Erice, 2008; Gürol ve Demirli, 2006; Piper, 2000; Tonbul, 2009). Benzer şekilde Barış (2011) tarafından 202 meslek lisesi öğrencisinin katılımı ile gerçekleştirilen çalışmanın sonuçları ile Demirli (2007) tarafından gerçekleştirilen ve web tabanlı elektronik portfolyo yazılımlarının derslerdeki akademik başarı ve tutum üzerindeki etkisinin incelendiği çalışmaların sonuçları da gerçekleştirilen araştırmanın bulgularını destekler niteliktedir. Benzer şekilde, ilgili alanyazın çalışmalarında, e-portfolyonun sosyal ağ sitesine entegrasyonu ile öğrenenlerin sosyal ă̆ sitesi üzerinden gerçekleştirdikleri paylaşımların arttığı ve paylaşımdaki bu artışın da e-portfolyo yazılımına olan bakışı daha olumlu hale getirdiği (Bartholomew, Jones ve Glassman, 2012; Cheng ve Chau, 2009; Salinas, Marin ve Escandell, 2011; Tur ve Marin, 2014), bireylerin kendilerini değerlendirme konusunda farkındalık ve yeti kazanmalarına olanak sağladığı ve otonomiyi geliştirdiği (Babaee, 2012; Lopez-Fernandez ve Rodriguez-Illera, 2009) belirtilmektedir. Bununla birlikte, öğretmen adaylarının öğretimde e-portfolyo kullanımına ilişkin tutumlarındaki bu olumlu değişimin, ilerleyen yıllarda gerek meslek hayatında gerekse özel hayatında bu yazılımları kullanma konusunda olumlu düşünceler içinde olmasına vesile olabileceği düşünülmektedir. Geleceğin öğretmenleri olacak öğrencilerimizin, e-portfolyonun öğretim sürecinde kullanımina ilişkin olumlu bir tutum içinde olmalarının eğitim-öğretim faaliyetlerinde bu yazılımları kullanmalarını sağlayacak ve dolayısıyla yeni neslin sadece sınav başarısıyla değil, daha 
bütüncül bir değerlendirme anlayışıyla yetişen bireyler olmalarına olanak tanıyacaktır.

Sosyal ağ sitesine entegre edilen bir e-portfolyo yazılımının öğretmen adaylarının akademik başarıları ve tutumları üzerindeki etkilerin incelendiği bu araştırmada, sosyal ağ sitesine entegre edilen e-portfolyo yazılımı kullanımının akademik başarıyı arttırdığı ve öğretimde e-portfolyo kullanımına ilişkin tutumları da pozitif yönde değiştirdiği ortaya çıkmışır.

Gerçekleştirilen araştırma belirli sınırlılıklara sahiptir. Araştırma bulgularının, nispeten küçük bir örneklem üzerinden elde edilmesi ve yazılımın sadece bir sosyal ağa entegre edilmiş olması araştırmanın en temel sınırlılıklarıdır. Her bir üniversitenin kendine özgü akademik ve sosyal yapısı olduğu göz önüne alınarak bundan sonraki araştırmaların farklı bölümlerde ya da farklı üniversitelerde öğrenim gören öğretmen adayları ile farklı derslerin öğretim sürecinde kullanılması ve sonuçların bu kapsamda değerlendirilmesi gereklidir.

\section{5. ÖNERİLER}

Geleceğin öğretmenleri olacak öğrencilerimizin, e-portfolyo kullanımına yönelik bakış açılarının değiştirilmesi ve yeni neslin akademik başarısında artışın sağlanabilmesi amacıyla, e-portfolyo öğrencilere tanıtılmalı ve öğretim sürecindeki değerlendirme faaliyetleri yeniden gözden geçirilerek e-portfolyo uygulamalarının kullanıldığı daha bütüncül değerlendirilmelerin işe koşulması gerektiği düşünülmektedir. Benzer şekilde, öğretim üyeleri ve öğretmenlere derslerinde e-portfolyo kullanımının önemini açıklayan, çeşitli akademik ve kişisel gelişim etkinlikleri gerçekleştirilebilir.

Bundan sonraki çalışmalarda, öğretmen adaylarının öğretim sürecinde e-portfolyo kullanımına ilişkin algıları ve akademik başarıları üzerinde etkili olabileceği düşünülen bilişsel ve davranışsal faktörleri ortaya çıkaracak farklı değişken ve ölçekler de eklenerek çalışmaya yeni bir boyut kazandırılabilir. Ayrıca, eportfolyo yazılımının farklı sosyal ağ siteleri ile olan entegrasyonunun akademik başarı ve tutum üzerindeki etkilerinin incelendiği nitel ve nicel çalışmalar gerçekleştirilebilir.

\section{Kaynakça}

Ahn, J. (2004). Electronic Portfolies: Blending Technology, Accountability \& Assessment. T.H.E. Journal, 31(9), 12-18.

Anderson, M. A. (2005). Yes, You Should Create A Professional Portfolio. Multimedia Internet School, 4, 34-36.

Babaee, M. (2012). E-portfolio in Social Media for Facilitating Language Learning. The Internet Journal of Language, Culture and Society, 35(2012), 29-35.

Bahçeci, D. (2006). Anatomi Dersinde Portfolyo Kullanmanın Öğrencilerin Bilişsel ve Duyuşsal Özellikleri Üzerine Etkisi. [The Effects of Using Portfolio Assesment in Anatomy Course on Students' Cognitive and Affective Skills]. (Yayınlanmamış Doktora Tezi). Gazi Üniversitesi, Eğitim Bilimleri Enstitüsü, Ankara, Türkiye. Yükseköğretim Kurulu Ulusal Tez Merkezi - Tez No:215382.

Barış, M. F. (2011). Bir Sosyal Ağ Sitesine E-Portfolyonun (Elektronik Gelişim Dosyası) Entegre Edilerek Uygulanması ve Sonuçlarmın İncelenmesi IIntegration of the E-Portfolio into A Social Network and Analysis of Results]. Trakya Üniversitesi, Fen Bilimler Enstitüsü, Bilgisayar Mühendisliği Anabilim Dalı, Edirne, Türkiye. Yükseköğretim Kurulu Ulusal Tez Merkezi - Tez No: 304652. 
Bartholomew, M., Jones, T. ve Glassman, M. (2012). A Community of Voices: Educational Blog Management Strategies and Tools. Tech Trends, 56(4), 19-25. doi: 10.1007/s11528-012-0583-3

Başçiftçi, R. (2011). Portfolyonun Fen ve Teknoloji Dersindeki Öğrenci Başarısı ve Kalıcılığa Etkisi. 2nd International Conference on New Trends in Education and Their Implications, 27th-29th April 2011, Antalya-Turkey, 311-316.

Barrett, H. (2000). Create Your Own Electronic Portfolio. Learning E Leading with Technology, 27(7), 14-21.

Black, P. ve Wiliam, D. (1998). Assessment and Classroom Learning. Assessment in Education, 5(1), 7-74.

Callaghan, N. ve Bower, M. (2012). Learning Through Social Networking Sites-the Critical Role of the Teacher. Educational Media International, 49(1), 1-17. doi:10.1080/09523987.2012.662621

Cerdà , F. L. (2012). Facebook's Potential for Collaborative E-Learning. RUSC, 8(2), 197-210.

Cheng, G. ve Chau, J. (2009). Digital Video for Fostering Self Reflection in an E-Portfolio Environment. Learning, Media and Technology, 34(4), 337-350. doi:10.1080/17439880903338614

Cheung, C. M. K., Chiu, P. Y. ve Lee, M. K. O. (2011). Online Social Networks; Why Do Students Use Facebook? Computers in Human Behavior, 27(4), 1337-1343.

Cotterill, S. J. (2007). What Is An Eportfolio? e-portfolios 2007, Maastricht. http://www.eportfolios.ac.uk/definition adresinden erişilmiştir.

Çayırcı, Ç. ve Altun, E. (2006). Yapılandırmacılık ve Elektronik Portfolyo Kullanımı (e-portfolyo). Ĕğitimde Çă̆daş Yönelimler-3: Yapılandırmacılık ve Ĕ̆itime Yansımaları. İzmir: Özel Tevfik Fikret Okulları.

Çayırcı, Ç. (2007). İlköğretim 7. Sinıfta Web Tabanlı Portfolyo Uygulaması: Fen Bilgisi ve Sosyal Bilgiler Örnekleri. [Web-Based Portfolio Application in Primary School 7th Grade: Samples of Sciences and Social Sciences]. (Yayınlanmamış Yüksek Lisans Tezi). Dokuz Eylül Üniversitesi, Eğitim Bilimleri Enstitüsü, Eğitim Programları ve Öğretim Bilim Dalı, İzmir, Türkiye. Yükseköğretim Kurulu Ulusal Tez Merkezi - Tez No: 211601.

Demir, S. (2012). Öğretmen Eğitimi Bağlamında Bir Öğrenme ve Değerlendirme Yöntemi Olarak Portfolyo. Erciyes Sosyal Bilimler Enstitüsü Dergisi, 32(1), 237-259.

Demirli, C. (2007). Elektronik Portfolyo Öğretim Sürecinin Öğrenen Tutumlarına ve Öğrenme Algılarına Etkisi. [The Effect of Electronic Portfolio Process on Learners' Attitudes and Learning Perceptions]. (Yayınlanmamış Doktora Tezi). Fırat Üniversitesi, Sosyal Bilimler Enstitüsü, Eğitim Bilimleri Anabilim Dalı, Elazı ̆̆, Türkiye. Yükseköğretim Kurulu Ulusal Tez Merkezi - Tez No: 206527.

Ediger, M. (1996). Portfolios, Pupils and the Teacher. Education Quarterly, 25(1), 4-55.

Ekici, M. ve Kıyıcı, M. (2012). Sosyal Ağların Eğitim Bağlamında Kullanımı. Uşak Üniversitesi Sosyal Bilimler Dergisi (2012) 5/2, 156-167.

Erdoğan, T. (2006). Yabancı Dil Öğretiminde Portfolyoya Dayalı Değerlendirmenin Öğrenci Başarısı ve Derse Yönelik Tutumlarına Etkisi. (Yayımlanmamış Yüksek Lisans Tezi). Dokuz Eylül Üniversitesi, Eğitim Bilimleri Enstitüsü, Eğitim Programları ve Öğretim Bilim Dalı, İzmir, Türkiye. Yükseköğretim Kurulu Ulusal Tez Merkezi - Tez No: 187179.

Erice, D. (2008). The Impact of E-Portfolio on the Writing Skills of Foreign Language Learners Studying at Abant Izzet Baysal University Basic English Program. [Elektronik Portfolyonun Abant İzet Baysal Üniversitesi Temel İngilizce Ĕ̆itimi Bölümü Öğrencilerinin Yazma Becerileri Üzerindeki Etkisi]. (Unpublished doctorate Dissertation). Gazi University, Institute of Educational Sciences, Department of English Language Teaching. Ankara, Turkey. Available from National Thesis Center of the Turkish Council of Higher Education database (Record No. 226917).

Geçer, A. K. ve Dağ, F. (2010). Üniversite Öğrencilerinin Bilgisayar Okur-Yazarlık Düzeylerinin Belirlenmesi: Kocaeli Üniversitesi Örneği. Yüzüncü Yıl Üniversitesi, Eğitim Fakültesi Dergisi, 6(1), 20-44.

Grace, C. (1992). The Portfolio and Its Use: Developmentally appropriate assessment of young children. Eric Digest. ED351150. http://www.ericdigests.org/1992-1/use.htm adresinden erişilmiştir. 
Gürol, M. ve Demirli, C. (2006). E-portfolio Sürecinde Öğrenci Motivasyonu. VI. Uluslararası Eğitim Teknolojileri Konferansı, Doğu Akdeniz Üniversitesi, Gazimağusa / KKTC, 19-21 Nisan, 2006.

Güven, E. ve Aydoğdu, M. (2009). Portfolyonun 6. sinıf Fen ve Teknoloji Dersi Vücudumuzdaki Sistemler Ünitesi'nde Başarı Ve Kalıcılığa Etkisi. Türk Fen Ĕ̆itimi Dergisi, 6, 115-126.

Hew, K. F. (2011). Students' and teachers' use of Facebook. Computers in Human Behavior, 27(2011), 662676.

Kabilan, M. K., Ahmad, N. ve Abidin, M. J. Z. (2010). Facebook: An Online Environment for Learning of English in Institutions of Higher Education? The Internet and Higher Education, 13(4), 179-187.

Karasar, N. (2012). Bilimsel Araştırma Yöntemi. 24. Baskı. Ankara: Nobel Yayın Dağıtım.

Kennedy, F., Bruen, J. ve Péchenart, J. (2012). Using an E-Portfolio to Facilitate the Self-Assessment of Both Language and İntercultural Learning in Higher Education: A Case-Study Approach. Language Learning in Higher Education, 1(1), 227-247. doi: 10.1515/cercles-2011-0015

Korkmaz, H. ve Kaptan, F. (2002). Fen Eğitiminde Öğrencilerin Gelişimini Değerlendirmek Için Portfolyo Kullanımı Üzerine Bir Inceleme. Hacettepe Üniversitesi Eğitim Fakültesi Dergisi, 23, 167-177.

Korkmaz, H. ve Kaptan, F. (2005). Fen Eğitiminde Öğrencilerin Gelişimini Değerlendirmek İçin Portfolyo Kullanımı Üzerine Bir İnceleme. The Turkish Online Journal of Educational Technology-TOJET, 4(1), 101-106.

Kutlu, M. O., Polat, Y. ve Döşlü, A. (2014). Ortaöğretim 10. Sınıf Bilgi ve İletişim Teknolojileri Dersinde Web Tabanlı Portfolyo Kullanımı-Adana İlinde Bir Çalışma. Ç.Ü. Sosyal Bilimler Enstitüsü Dergisi, 23(1), 336-351.

Lebuffe, J. R. (1993). Performance Assessment. Science Teacher, 60(6), 46-48.

Lee, M. J. W. ve McLoughlin, C. (2008). Harnessing the Affordances of Web 2.0 and Social Software Tools: Can We Finally Make "Student-Centered" Learning A Reality? Paper Presented at the World Conference on Educational Multimedia, Hypermedia and Telecommunications, Vienna, Austria.

Lockyer, L. ve Patterson, J. (2008). Integrating Social Networking Technologies in Education: A Case Study of a Formal Learning Environment. In Proceedings of 8th IEEE International Conference on Advanced Learning Technologies, 529-533, Spain: Santander.

Lopez-Fernandez, O. ve Rodriguez-Illera, J. L. (2009). Investigating University Students' Adaptation to a Digital Learner Course Portfolio. Computers \& Education, 52, 608-616.

Madge, C., Meek, J., Wellens, J. ve Hooley, T. (2009). Facebook, Social Integration and Informal Learning at University: It Is More for Socializing and Talking to Friends about Work than for Actually Doing Work. Learning, Media and Technology, 34(2), 141-155.

Masic, I., \& Sivic, S. (2011). Social networks in education of health professionals in Bosnia and Herzegovina - The role of pubmed/medline in improvement of medical sciences. Acta Inform Medica, 19(4), 196-202. doi: 10.5455/aim.2011.19.196-202

Mason, R., Pegler, C. ve Weller, M. (2004). E-Portfolios: An Assessment Tool for Online Course. British Journal of Educational Technology, 35(6), 717-727.

Mooney, C. (2009). Online Social Networking. D. A. Miller (Ed.). New York, NY: Gale Cengage Learning.

Özden, Y. (2003). Öğrenme ve Öğretme. Ankara: Pegema Yayıncılık.

Özyenginer, E. (2006). Bilgisayar Dersinde Elektronik Portfolyo Yöntemi Kullanımı Üzerine Bir Çalışma. [An Investigation on Using of Methot of Electronic Portfolio in a Computer Course]. (Yayınlanmamış Yüksek Lisans Tezi). Dokuz Eylül Üniversitesi, Eğitim Bilimleri Enstitüsü, Eğitim Programları ve Öğretim Bilim Dalı, İzmir, Türkiye. Yükseköğretim Kurulu Ulusal Tez Merkezi - Tez No: 189825.

Paulson, F. L., Paulson, P. R. ve Meyer, C. A. (1991). What Makes a Portfolio a Portfolio? Educational Leadership, 48(5), 60-63.

Pekkanlı, E. I. (2003). The Impact of the European Language Portfolio on the Learner Autonomy of Turkish Primary School Students. [Avrupa Dil Gelişim Dosyasının Türk Illköğretim Öğrencilerinin Öğrenen 
Özerkliğe Etkisi]. (Yayımlanmamış Doktora Tezi). Anadolu University Graduate School of Educational Sciences, Eskişehir, Turkey. Available from National Thesis Center of the Turkish Council of Higher Education database (Record No. 124618).

Pempek, T. A., Yermolayeva, Y. A. ve Calvert, S. L. (2009). College Students' Social Networking Experiences on Facebook. Journal of Applied Developmental Psychology, 30(3), 227-238.

Piper, C. H. (2000). Electronic Portfolios in Teacher Education Reading Methods Courses. Paper presented at the Annual Meeting of the American Educational Research Association, 24th-28th April 2000, New Orleans, LA, USA.

Prus, J. ve Johnson, R. (1993). Student Assessment Options: A Review and Critical Analysis. Paper Presented at English AAHE Conference on Higher Education Assessment, Chicago, IL.

Ryan, P. J. (1998). Teacher Development and Use of Portfolio Assessment Strategies and the Impact on Instruction in Mathematics. (Doctoral Dissertation). Stanford University School of Education, Stanford, CA.

Salinas, J., Marín, V. ve Escandell, C. (2011). A Case of Institutional PLE: Integration of VLE and E-Portfolio for Students. In: Proceedings of the PLE Conference 2011, 1-16. 10th - 12th July 2011, Southampton, UK. http://journal.webscience.org/585/ adresinden erişilmiştir.

Sánchez, R. A., Cortijo, V. VE Javedc, U. (2014). Students' Perceptions of Facebook for Academic Purposes. Computers \& Education, 70 (2014), 138-149.

Schacter, J. (1995). A Guide for Designing Performance Assessment. Los Angeles Learning Center Alternative Assessment Guidebook. Center for Research on Evaluation, Standards and Student Testing, University of California, Los Angeles, CA.

Selwyn, N. (2009). Faceworking: Exploring Students' Education-Related Use of Facebook. Learning, Media and Technology, 34(2) (2009), 157-174.

Simon, M. ve Forgette-Giroux, R. (2000). Impact of a Content Selection Framework on Portfolio Assessment at the Classroom Level. Assessment in Education, 7(1), 84-101.

Sivakumaran, T. (2005). Analysis of Teacher Candidates' and Faculty Evaluation of the Utility of a Single Digital Portfolio System. (Doctoral Dissertation). The University of Tennessee, Knoxville, USA. Available from ProQuest Dissertations and Theses database. (Document ID: 953995161).

Socialbakers (2013). Turkey Facebook Statistics. http://www.socialbakers.com/facebook-statistics/turkey adresinden erişilmiştir.

Stanciu, A., Mihai, F. ve Aleca, O. (2012). Social Networking as an Alternative Environment for Education. Accounting and Management Information Systems, 11(1), 56-75.

Stiggins, R. J. (1999). Assessment, Student Confidence, and School Success. Phi Delta Kappan, 81(3), 191198.

Tonbul, E. B. (2009). A Suggested E-Portfolio Model for ELT Students at Gazi University. [Gazi Üniversitesi İngilizce Öğretmenliği Bölümü Öğrencileri için Bir E-Portfolyo Model Önerisi]. (Unpublished Master Dissertation). Gazi University, Institute of Educational Sciences, Department of English Language Teaching, Ankara, Turkey. Yükseköğretim Kurulu Ulusal Tez Merkezi - Tez No: 228364.

Tur, G. ve Marin, I. V. (2014). Student Teachers' Attitudes toward Collaboration in E-Portfolios Built with Web 2.0 tools. UAE Journal of Educational Technology and eLearning, 5(2014), 58-65.

Turan, M. A. ve Sakız, G. (2014). Fen ve Teknoloji Dersinde Portfolyo Kullanımının Öğrenci Başarısı ve Kalıcılığa Etkisi. Mersin Üniversitesi Eğitim Fakültesi Dergisi, 10(3), 48-63.

Wade, A., Abrami, P. C., \& Sclater, J. (2005). An Electronic Portfolio to Support Learning. Canadian Journal of Learning and Technology, 31(3). http://cjlt.csj.ualberta.ca/index.php/

cjlt/article/view/94/88 adresinden erişilmiştir. 
54 | SAÜ Eğitim Bilimleri Enstitüsü

We Are Social (2015). Social, Digital \& Mobile in the Middle East, North Africa \& Turkey Report. http://www.slideshare.net/wearesocialsg/social-digital-mobile-in-the-middle-east-north-africaturkey?related $=4$ adresinden erişilmiştir.

Zeichner, K., ve Wray, S. (2001). The teaching portfolio in US teacher education programs: What We Know and What We Need to Know. Teaching and Teacher Education, 17(5), 613-621. 


\section{Extended Summary}

The aim of this study is to present the efficiency of e-portfolio software, which was integrated to Facebook social networking site. In this context, the data to be obtained from the study are expected to provide important contributions related with e-portfolio usage in higher education and enlighten the studies that will be made related with this subject. In the research trial model with control group and pretest with posttest was used. The research sample consists of 69 prospective teachers 48 of whom are male $(69.6 \%)$ and 21 of whom are female $(30.4 \%)$, who receive education in third grade of Trakya University Education Faculty Computer Education and Instructional Technologies Department and who take 'Multimedia Design and Development' lesson. In the research "Computer Literacy Scale" which was prepared by Geçer and Dağ (2010) was used in order to determine the computer literacy levels of prospective teachers. In order to determine the attitudes of prospective teachers related with e-portfolio usage and to monitor the attitude changes of participants, "Attitude Related with E-portfolio Teaching Process" scale, which was determined by Demirli (2007) was used. In order to determine the effects of eportfolio software on academic achievement and to determine the academic achievement change of control and experiment group in Multimedia Design and Development lesson, an academic achievement test was developed by researcher. Before application, academic achievement test was applied to randomly selected experiment and control groups while attitude scale related with e-portfolio teaching process scale was applied only to experiment group. After nine weeks of teaching process and application studies, same academic achievement test was applied to prospective teachers in experiment and control groups while attitude related with e-portfolio teaching process scale was applied to participants only in experiment group as posttest. In order to determine the permanence level five weeks after completion of applications aforementioned academic achievement test was replied by participants as followup test in experiment and control groups while attitude related with e-portfolio teaching scale was replied again by prospective teachers in experiment group in order to determine the attitude changes.

The e-portfolio software used in the research was developed by using asp.net software language (https://apps.facebook.com/e-portfolyo/). The software was subject to formative evaluation by field experts and prospective teachers during development stage. During this process, the errors which were not realized during coding stage were removed. Also under the scope of human computer interaction, visual elements such as screen design, menu arrangement, text order and text characters, pieces which cause usability problems and elements which were considered to cause overload in cognitive means on short term memory were reviewed and necessary adjustments were made. As a result of formative evaluation a group consisting of 3 field experts and 10 prospective teachers used the software in their lessons. After evaluative feedbacks received from lecturers and prospective teachers the software took its final form before application. As a result of the research in this study where effects of e-portfolio software, which was integrated to Facebook social networking site, on academic achievement and attitude, it was understood that the academic achievement point average of prospective teachers in experiment group who used the e-portfolio software that was integrated to social networking site were significantly higher than their classmates in the other group. In the follow-up test applied at the end of teaching process it was understood that the prospective teachers in experiment group had a significantly higher average compared to their friends in the other group, or in other words they forgot less the taught in- 
formation. Also the attitudes of prospective teachers in the experiment group towards e-portfolio software before the application, increased together with the application after their evaluation with the support of e-portfolio software which was integrated to Facebook social networking site. Attitudes related with e-portfolio usage in education which demonstrated a positive increase continued to stay positive five weeks after the end of the application. 